\title{
EVALUATION OF VEHICLE RUNNING SAFETY ON RAILWAY STRUCTURES DURING EARTHQUAKE
}

\author{
KEIICHI GOTO, MASAMICHI SOGABE \& MUNEMASA TOKUNAGA \\ Railway Technical Research Institute, Japan
}

\begin{abstract}
The vehicle running safety on structures during an earthquake is drawing great attention due to the increased frequency of large-scale earthquakes in recent years in Japan. In order to enhance the vehicle running safety on structures during an earthquake, it is important to reinforce existing structures in an effective and efficient way. On this point, it is needed to identify potential weak structures for the running safety in continuous railway structures, understand the dominant factor that contributes to causing derailment, and provide an appropriate reinforcement to the existing structures. In this study, we investigated the influence of various parameters related to the vehicle running safety on structures during an earthquake with simple dynamic structural models using the analysis program DIASTARS III that can consider the dynamic interaction between railway vehicles and railway structures. We also conducted seismic vehicle running analysis on a model line with $4.8 \mathrm{~km}$ in length and identified the weak structures for the running safety. Additionally, we proposed an index that is calculated only from structural responses with an earthquake and evaluates the ease of derailment. It was observed that the index could identify the critical structures on the running safety and evaluate the dominant factor.

Keywords: derailment, dynamic interaction, earthquake, numerical analysis, vehicle running safety.
\end{abstract}

\section{INTRODUCTION}

The vehicle running safety on structures, such as rigid-frame viaducts and girder-type viaducts, during an earthquake is drawing considerable attention due to the increased frequency of large-scale earthquakes in recent years. Hereafter, the seismic reinforcement of existing structures should consider not only the improvements in yield strength and deformability but also the improvements in the vehicle running safety on the structures during an earthquake or in the minimization of the risk of the vehicle derailment.

Accordingly, we developed a method to simulate the movement of vehicles during an earthquake over a stretch of structures with several kilometres long; on the basis of the simulation results, we calculated fragility curves (the occurrence probability of damage in relation to the intensity of earthquakes) on derailment and deviation to quantify the vehicle running safety on structures during an earthquake and the effects of several countermeasures against derailment and deviation [1,2]. However, the evaluation on the fragility curves is a macroscopic approach that focuses on an entire group of structures along the stretch; therefore, we have not been able to identify specific structures among a group that may cause derailment to occur. In order to reinforce the existing structures in an effective and efficient manner to ensure the enhanced vehicle running safety during an earthquake, it is important to identify potential weak structures for the vehicle running safety while understanding the impact of dominant factors, such as vibration displacement of structures and differential displacement on the borders of structures, that are observed during an earthquake and to provide an appropriate seismic reinforcement for the dominant factors.

On the basis of such a background, as for vibration and differential displacements [3], which are two dominant factors that affect the vehicle running safety on structures during an earthquake, this study clarified the impact of various parameters of both displacements on the 
running safety. This study also included the numerical simulation of vehicles running on a continuous structure line during an earthquake and aimed at analysing the derailment locations in detail, thereby identifying relatively weak structures that could affect the vehicle running safety in the line during an earthquake. Furthermore, a quantitative evaluation was conducted on the weak structures and all other structures in the line to evaluate the impact of the vibration and differential displacements on the vehicle running safety during an earthquake.

\section{METHOD OF NUMERICAL ANALYSIS}

This study described below uses DIASTARS III [4-7], which is a numerical analysis program for dynamic interaction between railway vehicles and railway structures with capability of analysis of vehicle behaviour before, during and after derailment.

\subsection{Dynamic model of a vehicle}

Figure 1 depicts the dynamic model of a vehicle. One vehicle consists of one car body, two truck frames and four wheelsets and each of these components is modelled as rigid body. These rigid body components are connected to each other via springs and dampers to assemble as a three-dimensional model. One vehicle has 31 degrees of freedom. An actual vehicle has stoppers between those components to prevent the occurrence of large relative displacements between these. In order to consider this, bilinear springs are used for the springs. In this study, a train is composed of several vehicles. The validity of the dynamic model has already been proven through vibration experiments using a vibration table and full-scale model vehicle [8]. The specifications for the vehicle in this study were determined on the basis of the recent specifications of the Shinkansen vehicle.

\subsection{Dynamic model of railway structures}

In DIASTARS III, arbitrary structures and track type can be modelled using a variety of finite elements such as beams, shells, solids and springs so on. The dynamic model of the structures used in this study is described in detail later.

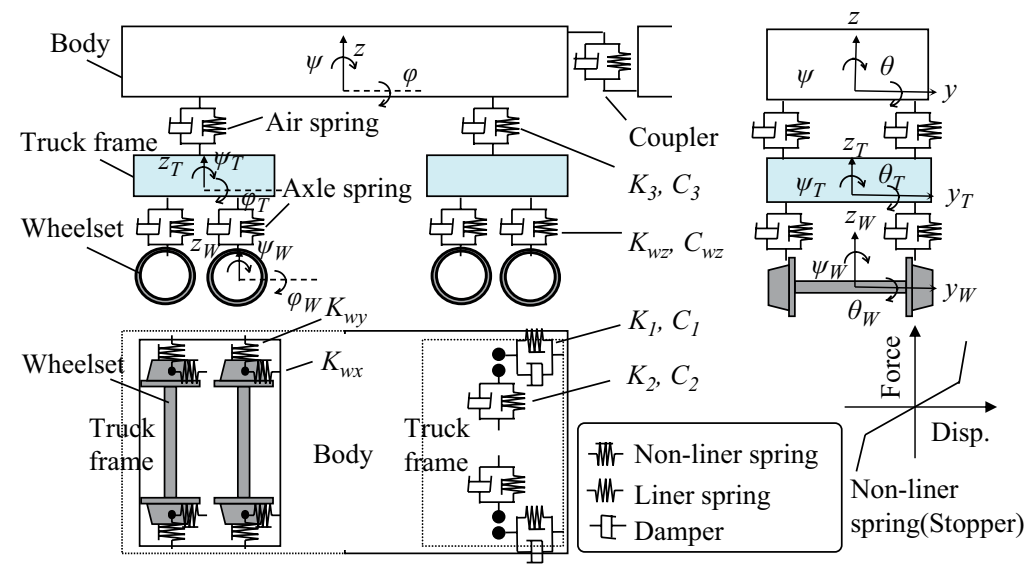

Figure 1: Dynamic model of a vehicle. 

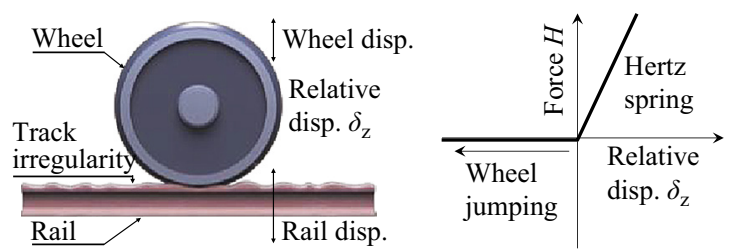

(a)
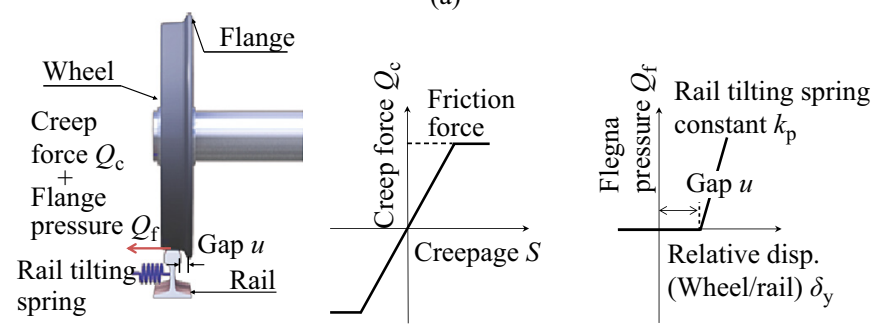

(b)

Figure 2: Interaction model between a wheel and rail before derailment: (a) vertical direction and (b) lateral direction.

\subsection{Interaction model between a wheel and rail}

Figure 2 depicts the interaction model between a wheel and rail before derailment. DIASTARS III uses a conventional dynamic model for wheel/rail contact before derailment.

The dynamic interaction is calculated based on their contact points and angle while considering their precise geometric forms. The contact force between the wheel and rail is calculated using a contact spring on the basis of the Hertz contact theory. The vertical lift of the wheel off the rail is also considered. In the horizontal direction, a creep force acts on the contact surface in a tangential direction when the wheel flange is not in contact with the rail. The creep force is a tangential force caused by the creep (slip) that is generated when the wheel rolls on the rail. The creep force is saturated to the friction force when the creepage becomes high. When the wheel flange is in contact with the rail, the flange pressure that is based on the rail tilting spring of the rail acts on the contact surface in the normal direction.

Since this study primarily focuses on the evaluation of vehicle behaviour up to the derailment, it is mentioned that only the outline of the interaction model between a wheel and track structures after derailment. DIASTARS III can compute the contact between derailed wheels and various track structures, such as slabs, sleepers, vehicle guide devices and rails, using a combination of finite element method (FEM) and rigid cross-sectional models. To obtain details of the interaction model after derailment, refer to Ref. [6].

\subsection{Numerical method}

DIASTARS III solves a system of equations of motion for vehicles and railway structures, thereby, performing dynamic coupled analysis of multiple vehicles and railway structures. For efficient numerical analysis, the equations of motion for vehicles and railway structures are subjected to modal transformation. The equations of motion on a modal coordinate system that is obtained through this process are solved for each time increment using Newmark's 


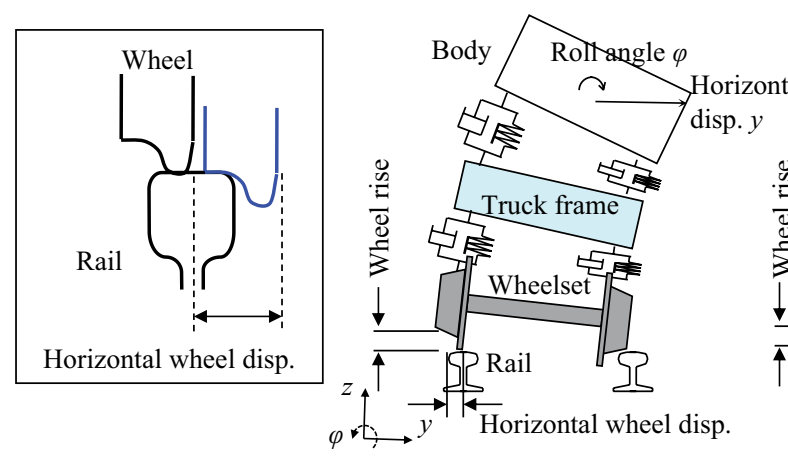

(a)

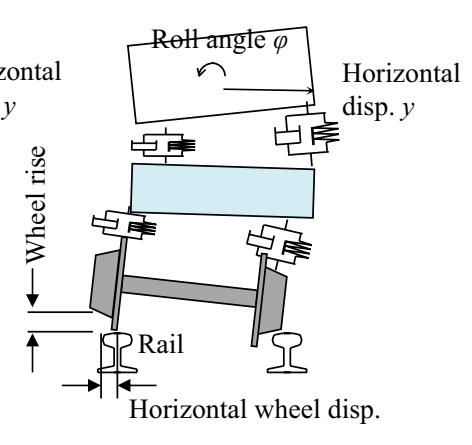

(b)

Figure 3: Criterion for the vehicle running safety and the derailment modes during an earthquake: (a) lower centre rolling and (b) upper centre rolling.

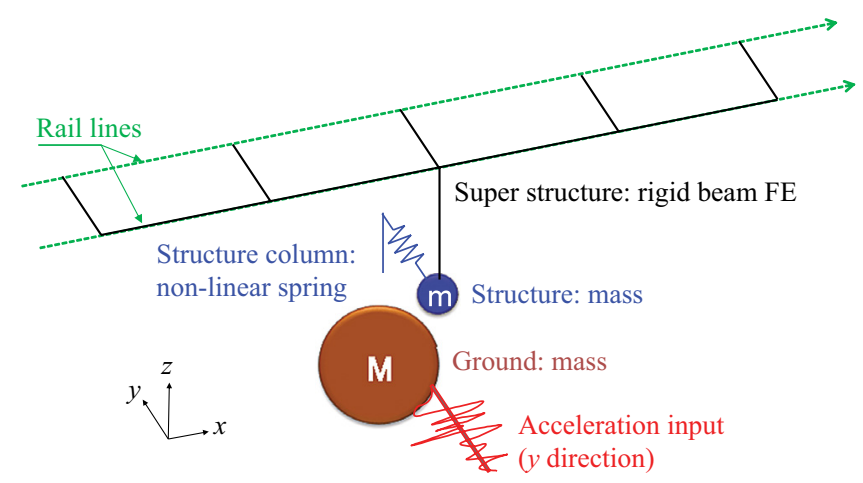

Figure 4: Dynamic model of a structure.

constant average acceleration method. Since these equations of motion are non-linear, the iterative calculation is repeated within the time increment until the unbalance forces become sufficiently small. In this study, the time increment was set to $10^{-4} \mathrm{~s}$.

\subsection{Evaluation criterion for the vehicle running safety during an earthquake}

Figure 3 depicts the criterion for the vehicle running safety and the derailment modes during an earthquake. The criterion refers to the horizontal displacement of wheels relative to rails (hereafter referred to as "horizontal wheel displacement"). In this study, the threshold for the derailment of vehicles was set to $70 \mathrm{~mm}$, which corresponds to the value of the wheel immediately before derailing. The horizontal wheel displacement rapidly increases when the wheel rise, which is shown in Fig. 3, exceeds the flange height (30 mm for the Shinkansen). The vehicle derailment modes during an earthquake are classified broadly into lower and upper centre rolling. The lower centre rolling mode occurs at approximately $0.8 \mathrm{~Hz}$ or less and the upper centre rolling mode typically occurs at approximately $1.3 \mathrm{~Hz}$ and more. These modes are differentiated on the basis of the phase of the horizontal and rolling motions of the vehicle. 


\section{SAFETY LIMITS FOR VIBRATION AND DIFFERENTIAL DISPLACEMENT}

This section discusses the impact of various parameters for the running safety, such as magnitude of earthquakes, yield seismic coefficient of structures, train speed and so on, in terms of both vibration displacement and differential displacement. There are two types of differential displacement. One is "alignment irregularity" and the other is "angular rotation" [3]. This study focuses only on the angular rotation.

\subsection{Numerical analysis conditions}

\subsubsection{Vibration displacement}

Figure 4 depicts the dynamic model of a structure that is used to evaluate the running safety for vibration displacement. The structure was modelled as a one-degree-of-freedom system with a tri-linear skeleton curve and standard hysteretic characteristics. For the skeleton curve, the parameters used include equivalent natural period, $T_{\text {eq }}$, yield seismic coefficient, $k_{\text {hy }}$, and maximum seismic coefficient, $k_{\text {hmax }}$. The secondary slope for the post-yield behaviour of the structure was set to be one-tenth of the primary slope, whereas the tertiary slope for the post-peak behaviour of the structures was set to be one-hundredth of the primary slope. The structure mass was set to be 20 times the mass of the vehicle. The equivalent natural period was adjusted to the specified values by varying the initial (primary) slope of the structure's column springs. The large masses for acceleration inputs representing the ground was set to be 1,000 times the mass of the structure. A 5\% damping ratio was applied to the structure.

Table 1 presents the parameters that are used to evaluate the running safety for the vibration displacement. The following were used as input waveforms: sine waves buffered at both the start and end (single wave and five waves); Level-2 Spectrum I design earthquake motion of ocean-trench type for G2 ground and Level-2 Spectrum II design earthquake motion of inland active faults type for G2 ground (hereafter referred to as "L2 Spec. I (G2)" and L2 Spec. II (G2)", respectively) [9]. Here, Level-2 means large scale earthquake and G2 ground mean diluvium that has 0.25 and shorter ground natural period. Figure 5 shows these time-history waveforms and the elastic acceleration response spectra for the L2 earthquake motions. This figure additionally presents the information on Level-1 design earthquake motion for G2 ground (L1 (G2)). L1 earthquake motion has the return period of 50 years and the vehicle running safety has to be ensured under it. In this study, the sine waves were used to clarify the fundamental vehicle performance against specific periodic excitations while the design earthquake motions were used to evaluate the impact of the structural vibration characteristics on the running safety. The vehicle used was a one-car vehicle that was running at $320 \mathrm{~km} / \mathrm{h}$.

Table 1: Parameters used for evaluating the running safety for the vibration displacement.

\begin{tabular}{llllll}
\hline Wave type & Input wave & Max. acc. (gal) $T_{\text {eq }}(\mathrm{s})$ & $k_{\mathrm{hy}}$ & $k_{\mathrm{hmax}}$ \\
\hline Sine wave & 1 and 5 waves (period) & $300-2,280$ & - & - & - \\
& $0.1-2.0 \mathrm{~s}$ & (every 20) & (rigid) & (rigid) & (rigid) \\
Design wave & .L2Sp c.I (G2) & $20-2,000$ & $0.1-2.0$ & $0.3,0.7,100$ & $1.2 k_{\text {hy }}$ \\
& .L2Sp c.II(G2) & (every 20) & (every 0.1) & & \\
\hline
\end{tabular}



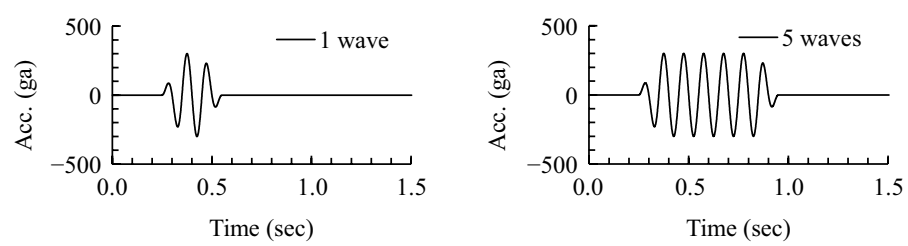

(a)
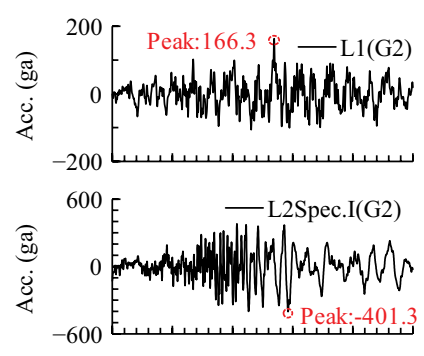

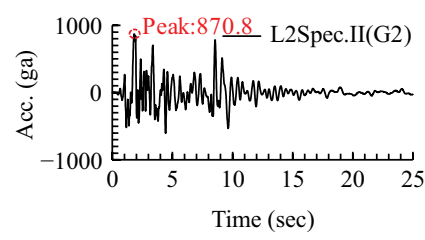

(b)

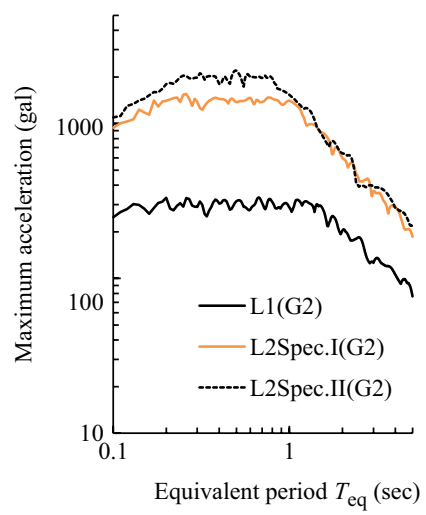

(c)

Figure 5: Time-history waveforms and the elastic acceleration response spectra: (a) timehistory waveforms of sine waves; (b) time-history waveforms of Design earthquake motions; (c) elastic acceleration spectra.

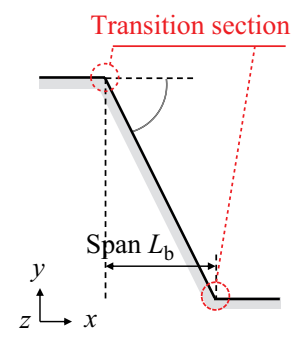

(a)

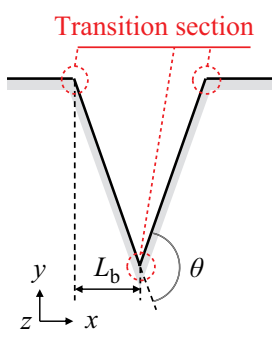

(b)

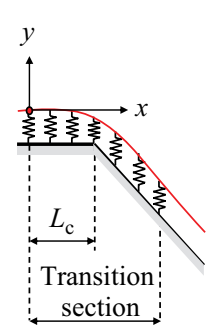

(c)

Figure 6: Standard forms of differential displacement (angular rotation) and a transition section: (a) parallel shift; (b) folding; (c) transition section.

Table 2: Parameters used for evaluating the running safety for the differential displacement.

\begin{tabular}{|c|c|c|c|c|}
\hline $\begin{array}{l}\text { Angular } \\
\text { rotation type }\end{array}$ & Span (m) & $\begin{array}{l}\text { Rotation angle } \\
\text { (mrad) }\end{array}$ & $\begin{array}{l}\text { Number of angular } \\
\text { rotation }\end{array}$ & eed $(\mathrm{km} / \mathrm{h})$ \\
\hline $\begin{array}{l}\text { Parallel shift } \\
\text { folding }\end{array}$ & $10-50$ (every 10$)$ & $1-30$ (every 1$)$ & $1,3,5$ & $\begin{array}{l}100-400 \\
\text { (single-car) }\end{array}$ \\
\hline
\end{tabular}




\subsubsection{Differential displacement}

Figure 6 depicts the standard forms of differential displacement (angular rotation) and a transition section. The angular rotation was modelled as lateral track irregularity on a rigid track. The angular rotation forms were fixed in space and were drawn on the basis of the design standards [3]. At each end of the girders at which angular rotation occurs, a transition section was arranged to avoid out the discontinuity of curvature, as indicated by the following equations:

$$
\begin{gathered}
0 \leq x \leq L_{\mathrm{c}} \\
y=\frac{\theta}{4 \beta} e^{\beta\left(x-L_{c}\right)}\left\{\cos \beta\left(x-L_{\mathrm{c}}\right)+\sin \beta\left(x-L_{\mathrm{c}}\right)\right\} \\
L_{c}<x \leq 2 L_{\mathrm{c}} \\
y=\frac{\theta}{4 \beta} e^{-\beta\left(x-L_{\mathrm{c}}\right)}\left\{\cos \beta\left(x-L_{\mathrm{c}}\right)-\sin \beta\left(x-L_{\mathrm{c}}\right)\right\}+\theta\left(x-L_{\mathrm{c}}\right)
\end{gathered}
$$

where $L_{\mathrm{c}}$ is half of the transition length, $\theta$ is the level of angular rotation at the girder end, $x$ is the distance from the beginning of the transition section and $\beta$ is the relative flexural rigidity of beams on the elastic foundation that can be given as

$$
\beta=\sqrt[4]{k / 4 E I}
$$

where $k$ is the track support spring constant in the lateral direction per unit length and $E I$ is the flexural rigidity of the track in the lateral direction. The track structure was assumed to be a slab track $\left(k=480 \mathrm{~N} / \mathrm{mm} / \mathrm{mm}, E I=1.02 \mathrm{MN}-\mathrm{m}^{2}\right)$.

Table 2 presents the parameters used for evaluating the running safety for the differential displacement. In case of both parallel shift and folding, various span lengths, rotation angles, number of girders and train speeds were used. Further, a single vehicle was used.

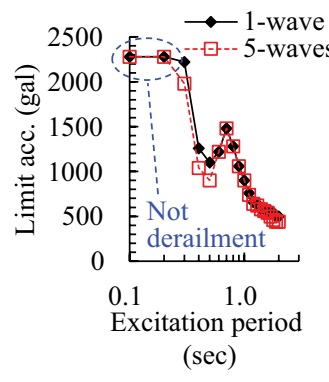

(a)

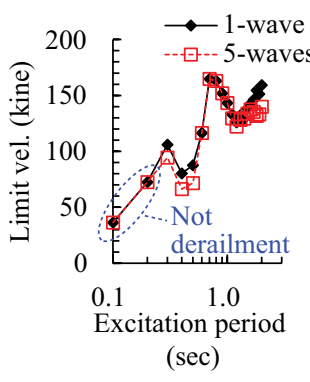

(b)

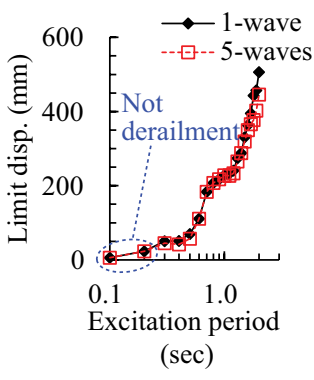

(c)

Figure 7: Safety limits for vibration displacement under the sine wave inputs: (a) limit acceleration, (b) limit velocity and (c) limit displacement. 


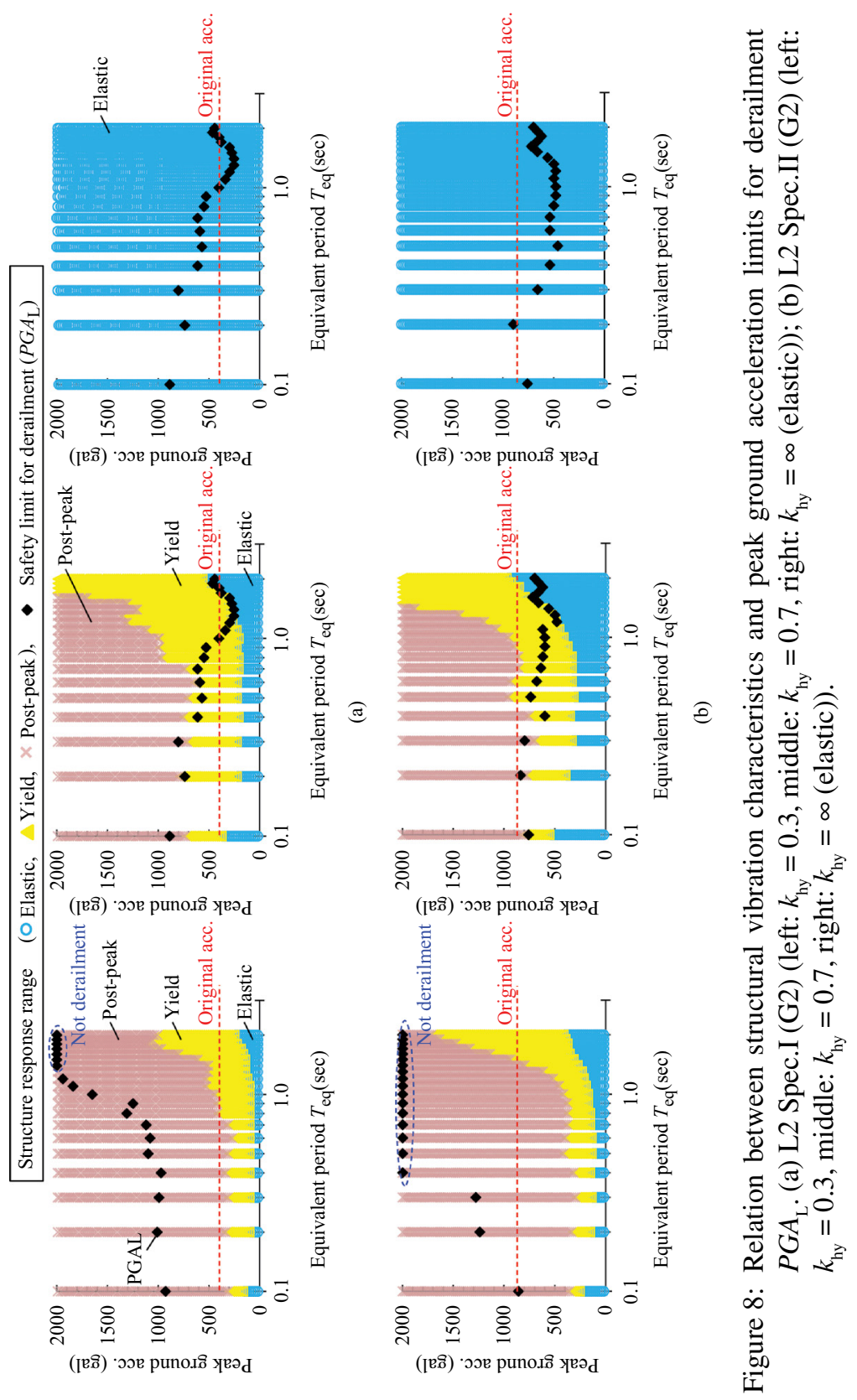




\subsection{Numerical analysis results}

\subsubsection{Vibration displacement}

Figure 7 depicts the safety limits for derailment under the sine wave inputs. For the limit of the acceleration, the thresholds are depicted to decrease as the period of the input waves increases. Additionally, the threshold peak is observed at a vibration period of approximately $0.7 \mathrm{~s}$, which is in the transition area between the lower centre rolling and the upper centre rolling. Five-wave sine waves, which easily induce the lower- and upper-centre rolling, depict approximately $15 \%$ lower thresholds than those depicted by the single-sine waves.

Figure 8 depicts the relation between structural vibration characteristics and peak ground acceleration limits for derailment (hereafter " $P G A_{\mathrm{L}}$ ", which is the maximum input ground acceleration at which vehicles do not derail) in respect to the design earthquake motions. This figure indicates the relation between the structural response range (elastic region, yield region and post-peak region) with specific equivalent natural period $T_{\text {eq }}$ and $P G A_{\mathrm{L}}$, with respect to the peak ground acceleration $(P G A)$ of the design earthquake motions. As depicted in the figure, at low yield seismic coefficient, the structures tend to yield before vehicle derailment, resulting in case in which seismic force is not transmitted to the vehicle, which further increases the $P G A_{\mathrm{L}}$. The trend indicates that the vehicle running safety under vibration displacement improves as the structural response becomes nonlinear and structures have a longer natural period. This can also be observed in Fig. 7(c), which indicates depicts that the limit displacements under the sine wave inputs increases with long vibration periods. Conversely, it is presumed that differential displacement increases, thereby heavily affecting the vehicle running safety while the vehicles are running on the boundary between structures with low yield seismic coefficients. A comparison of the design earthquake motions based on the same $P G A$ for high yield seismic coefficients ( 0.7 or more in the figure) depicts that L2
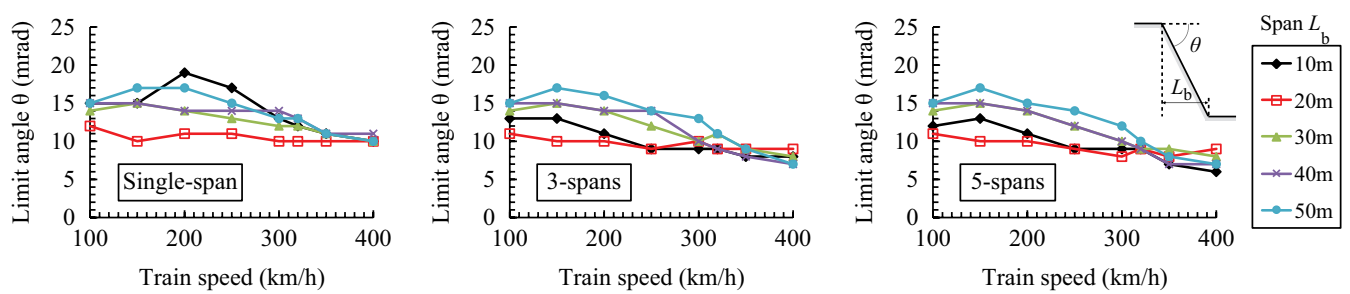

(a)
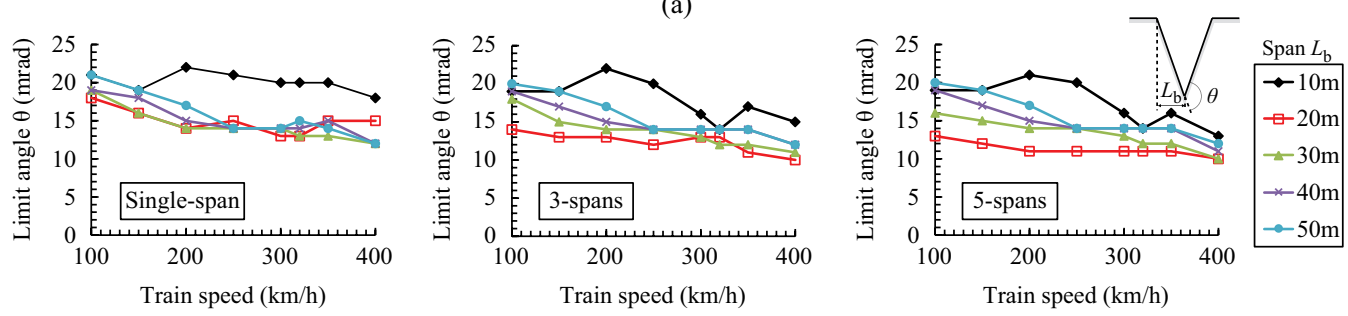

(b)

Figure 9: Safety limits for differential displacement. (a) Parallel shift (left: single-girder, middle: three-girders, right: five-girders; and (b) folding (left: single-girder, middle: three-girders, right: five-girders. 

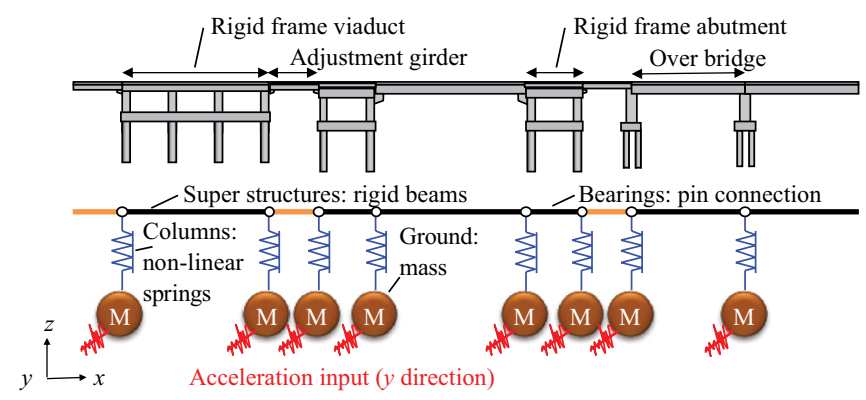

Figure 10: Dynamic model of structures in a continuous structure line.

Spec. I, which contains repeated waves with large amplitudes, tends to exhibit lower safety limits than that exhibited by L2 Spec. II. With reference to $P G A$ of the original waves that have been provided in Fig. 8, the graphs for a yield seismic coefficient of 0.7 or more indicate that the vehicle derails by only vibration displacement in response to L2 Spec. II and whether the derailments occur or not in response to L2 Spec. I varies in accordance with the structural equivalent natural period $T_{\text {eq }}$.

\subsubsection{Differential displacement}

Figure 9 depicts the influence of the train speed, span of girder and number of girders on the safety limit angle. In terms of both parallel shift and folding, the safety limit angles tend to get low at high train speeds and large numbers of girders. For example, on the combined parameters of folding, single girder and $20 \mathrm{~m}$ span, the limit angle for a train speed of $300 \mathrm{~km} / \mathrm{h}$ is observed to be approximately $28 \%$ lower than that observed in case of a train speed of $100 \mathrm{~km} / \mathrm{h}$. Further, in case of a vehicle speed of $300 \mathrm{~km} / \mathrm{h}$, the limit angle with a five-girder is approximately $15 \%$ lower than that observed in case of a single-girder. For span-based comparison, the overall $20 \mathrm{~m}$ span is observed to exhibit the lowest limit angle. By comparing spans of $20 \mathrm{~m}$ and longer, we observe that long spans tend to have high limit angles.

\section{THE DOMINANT FACTOR ON DERAILMENT IN A CONTINUOUS STRUCTURE SECTION}

On the basis of the observations related to the impact of vibration and differential displacements on the running safety limits in Section 3, this section discusses the numerical simulation that is conducted to investigate the vehicle running safety during an earthquake in a continuous structure line which is modelled based on an actual Shinkansen line, identifies the relatively weak structures for the vehicle running safety and examines which factor (vibration displacement or differential displacement) is dominant for derailment on these structures.

\subsection{Numerical analysis conditions}

Figure 10 depicts the dynamic model of structures in a continuous structure line. Each pier represented by a nonlinear spring while columns of a rigid frame viaduct and rigid frame abutment are represented by two nonlinear springs, one at each end, to model their horizontal response in a perpendicular $(y)$ direction to the rails. The upper layer of each block of rigid 
frame viaducts, rigid frame abutments, adjustment girders and over bridges are modelled in the form of sufficiently rigid beams. Further, the structures are hinge-coupled. The nonlinearity of each structure column is modelled by using nonlinear horizontal springs with a standard tri-linear type based on the skeleton curves that were obtained through pushover analyses with 2D model. The pushover analyses were conducted on two to four structures with standard heights for each structural type. The nonlinear properties for the structure heights for which pushover analyses were not conducted were determined by interpolating that of the structures for which pushover analyses were conducted. At the bottom end of each structure column, a large mass having a mass that is 1,000 times that of structural mass was put for acceleration input. The structural mass is determined based on the design calculations for actual concrete structures. The damping ratio of the structures was given $5 \%$.

Figure 11 depicts the structural arrangement and vibration characteristics of the continuous structure line, which is approximately $4.8 \mathrm{~km}$ long and is primarily comprised of the adjustment-girder-type rigid-frame viaducts and girder-type viaducts of varying heights. The various spans are used as follows: $25-35 \mathrm{~m}$ for rigid-frame viaducts $(8-10 \mathrm{~m}$ for adjustment girders) and 9-40 m for girder-type viaducts. Rigid-frame viaducts with heights of $12 \mathrm{~m}$ or more are considered to be two-layer structures, which cause extensively different vibration characteristics (equivalent natural period and yield seismic coefficient) before and after each viaduct. This is indicated by the extensively fluctuating equivalent natural period at the locations at which the structural type and/or height changes as shown in Fig. 11.

A 12 -vehicle train (300 $\mathrm{m}$ in total length) was run at $320 \mathrm{~km} / \mathrm{h}$. To evaluate the vehicle running safety over the entire structure line during an earthquake, the train was run for a total of 20 scenarios, with each start point shifted by $300 \mathrm{~m}$, to virtually cover the entire line. As the seismic inputs, L1 (G2), L2 Spec. I (G2) and L2 Spec. II (G2), depicted in Fig. 5 were used and the $P G A$ was increased by 50-gal increment between 50 gal and 1,000 gal. A 576-core Cray XC 30 parallel processor was used, which took approximately $52 \mathrm{~h}$ to process all the scenarios (20 scenarios with different staring points $\times 20$ scenarios with different $P G A \times 3$ different earthquake motions $=1,200$ scenarios).

\subsection{Numerical analysis results}

Figure 12 depicts the maximum response displacements and rotation angles for a PGA of 100-600 gal with L2 Spec. I (G2). It is depicted that several structures begin to yield at a $P G A$ of approximately $200 \mathrm{gal}$ and that the maximum response displacements are substantially increased at higher $P G A$ s. The rotation angles are high between the structures where

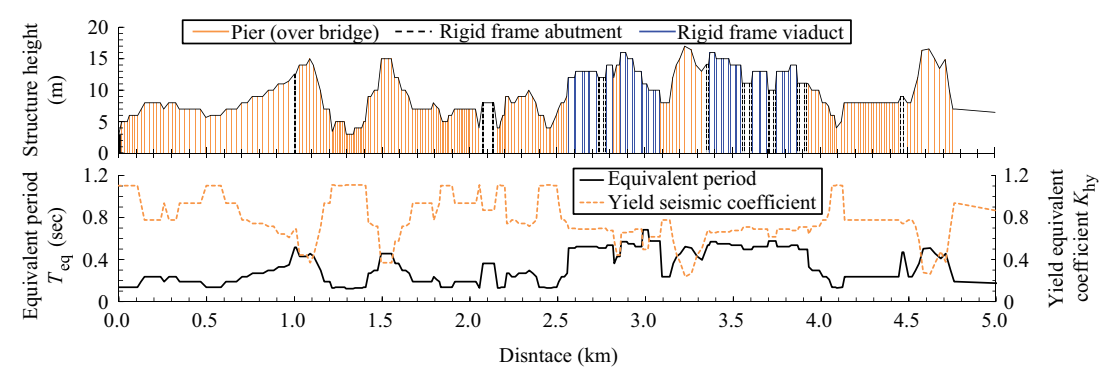

Figure 11: Structural arrangement and vibration characteristics of the continuous structure line. 


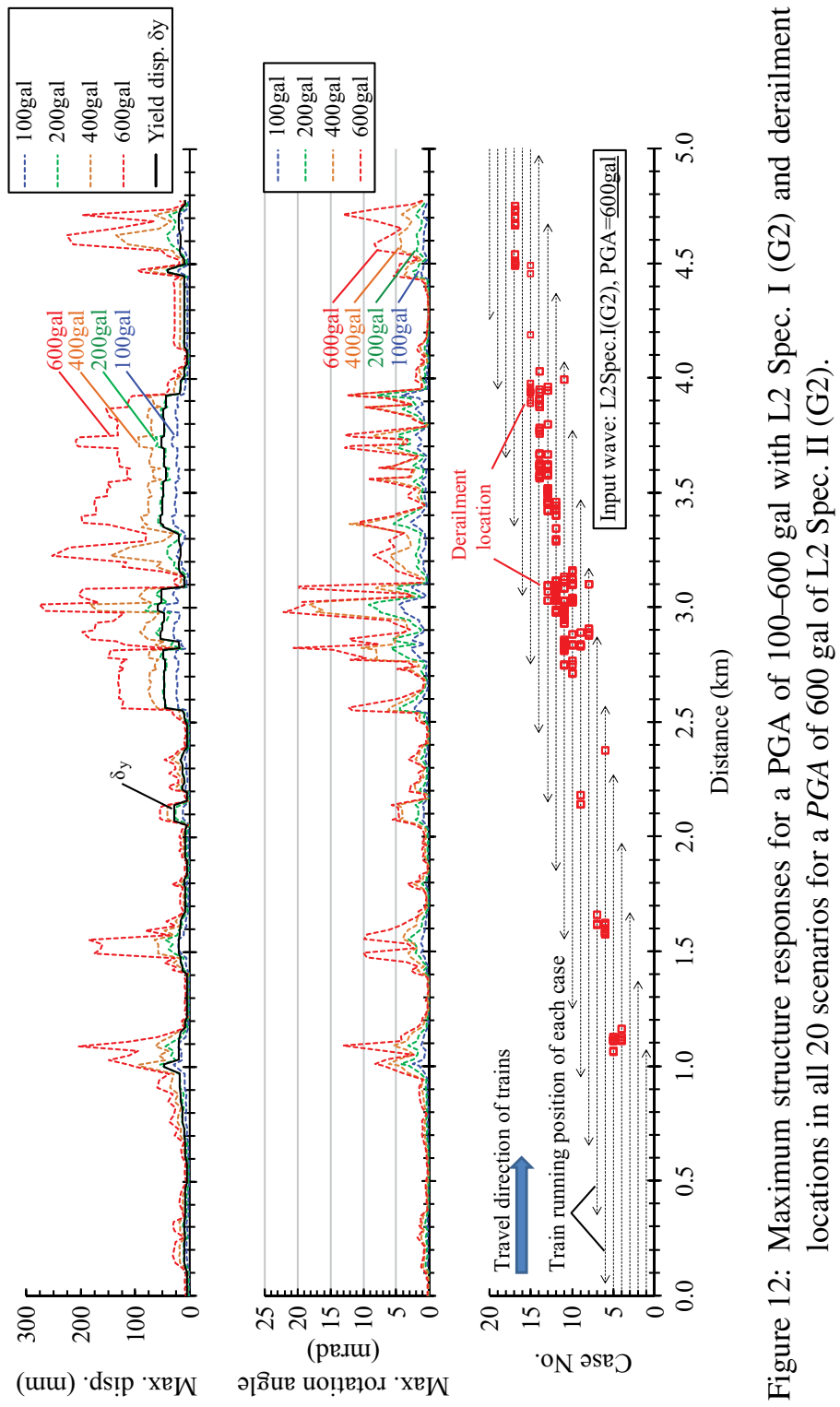


the structures yielded and where the equivalent natural periods were different. The greatest rotation angle was observed at approximately $3.0 \mathrm{~km}$ at the end of the adjustment between a single-layer rigid-frame viaduct and a double-layer rigid-frame viaduct. The single-layer rigid-frame viaduct yielded, which increased the relative displacement between the viaducts, subsequently increasing the rotation angle. Figure 12 also depicts the derailment locations in all 20 scenarios for a PGA of 600 gal of L2 Spec. II (G2). These locations mean where the horizontal wheel displacement exceeded $\pm 70 \mathrm{~mm}$ for the first time considering the start points of each wheelset and the train speed. The horizontal wheel displacement exceeded \pm 70 mm just after the wheel passed the weak structure in question, which indicates that there is a slight delay between the locations of the weak structures and the locations of the derailment. The figure also indicates that derailments occur when the angular rotation is large indicating that differential displacement (angular rotation) exhibits a higher impact than that exhibited by vibration displacement in this line while determining the vehicle running safety during an earthquake. This is also indicated that since the structures begin to yield at a $P G A$ of approximately 200 gal, the structural yield apparently increases the $P G A_{\mathrm{L}}$, as depicted in Fig. 8, and the maximum rotation angles are close to the limit angles in cases of the folding (around $10-15 \mathrm{mrad}$ at $320 \mathrm{~km} / \mathrm{h}$ ), as depicted in Fig. 9.

Figure 13 depicts the $P G A_{\mathrm{L}}$ for the design earthquake motions. Each $P G A_{\mathrm{L}}$ is plotted at the locations where trains were running when the PGA of each design earthquake motions occurred. This presentation method has been used over past years [1,2], and indicated the tendency of $P G A_{\mathrm{L}}$ and the influences of different seismic waves that are observed throughout the entire structure section, however, the method can only approximately estimate the location of the weak structures on the vehicle running safety.

\subsection{Analysis of the dominant factor for derailment}

Figure 14 depicts the relation between the derailment location and the derailment index, $I_{\mathrm{d}}$, of structures with PGA values of 400, 600 and $900 \mathrm{gal}$ in response to L2 Spec. I (G2). The derailment index, $I_{\mathrm{d}}$, is a parameter that is newly defined in this study to analyse the dominant factors in derailment, and is calculated using eqn. (3) based on the safety limits for the vibration displacement and differential displacement discussed in Section 2. The first and second terms of the equation represent the ease of derailment with vibration displacement and the ease of derailment with differential displacement, respectively. In this study, these components are simply added together to evaluate the comprehensive ease of derailment on a structure.

$$
I_{\mathrm{d}, \mathrm{i}}=\delta_{\mathrm{i}} / \delta_{\mathrm{L}, \mathrm{i}}\left(T_{\mathrm{eqs}}\right)+\theta_{\mathrm{i}} / \theta_{\mathrm{L}, \mathrm{i}}
$$

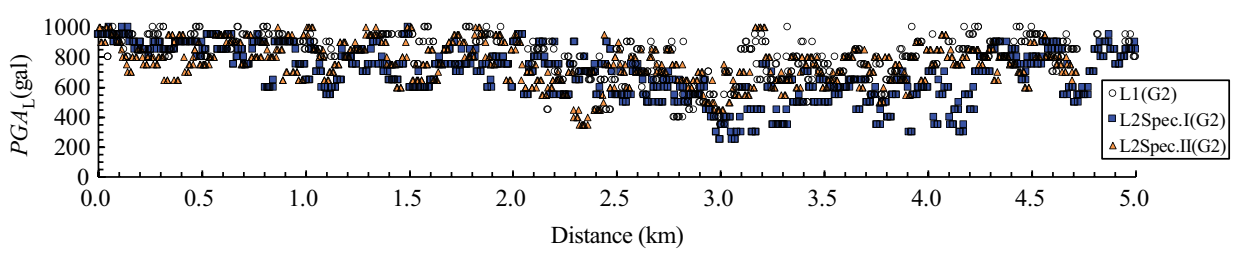

Figure 13: $P G A_{\mathrm{L}}$ for the design earthquake motions. 
where, $i$ is the structure number, $\delta$ is the maximum displacement of the structure, $\delta_{\mathrm{L}, \mathrm{i}}$ is the safety limit for the vibration displacement for the five-wave sine wave that is depicted in Fig. 7 (c), $\theta_{\mathrm{i}}$ is the maximum rotation angle between the structures, $\theta_{\mathrm{L} . \mathrm{i}}$ is the safety limit for the differential displacement that is depicted in Fig. 9, $\delta_{\mathrm{L}, \mathrm{i}}$ is a function of the secant equivalent natural period, $T_{\text {eqs }}$, that is calculated based on the secant rigidity as shown in Fig. 15 to consider the impact of the nonlinearization of structures. $\theta_{\mathrm{L} . \mathrm{i}}$, which is dependent on the angular rotation type, span, train speed and numbers of girders, is simply set to $15 \mathrm{mrad}$ by considering fig. 9. The vibration displacement and differential displacement do not necessarily contribute equally to the safety limits, therefore, the structures for which the sum of both the displacements exceeds one are considered to not necessarily cause derailment. In contrast, Fig. 14 depicts the derailment locations where there are structures with a derailment index, $I_{\mathrm{d}}$, exceeding approximately 1.0. By observing the $P G A$ of 400 -gal input in Fig. 14, the structures on which derailment occurred were observed to be more heavily affected by differential displacement as compared to the remaining structures, indicating that these derailments could be attributed to differential displacement. By observing the PGA of 900-gal input, we notice that derailment occurred throughout the entire section. However, in some areas, such as the structures at $4.1-4.4 \mathrm{~km}$, the derailment was mainly caused by vibration displacement. The above result indicates that the derailment index, $I_{\mathrm{d}}$, is effective in identifying the weak structures and the dominant factor that contributes to derailment in the continuous structure group.

The vehicle running safety during an earthquake in the continuous structure group set up for this study was predominantly affected by differential displacement. This, however, is also considered to depend on the structural vibration characteristics (equivalent natural period, yield seismic coefficient, damping ratio and so on), the arrangement of structures, ground type, earthquake motions, train speed and other parameters. In future, efforts will be devoted to improve the accuracy of the derailment index, $I_{\mathrm{d}}$, by expanding the scenarios

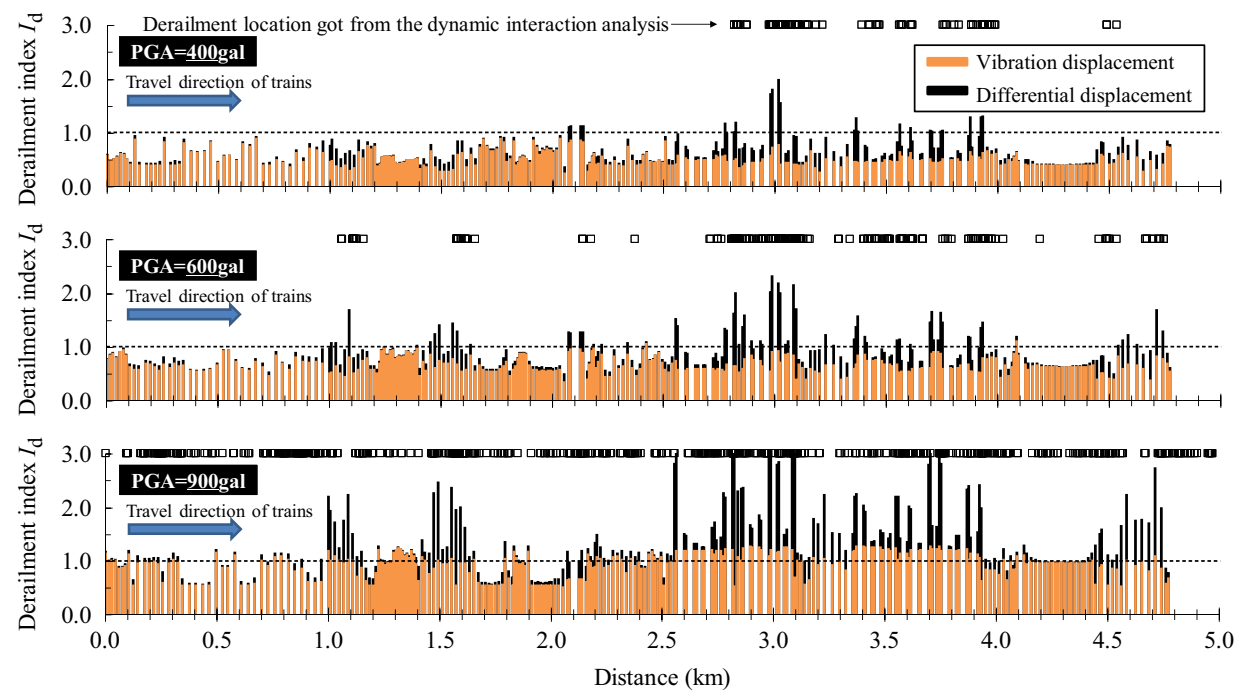

Figure 14: Relation between the derailment locations and the derailment index, $I_{\mathrm{d}}$, of structures with $P G A$ values of 400, 600 and 900 gal in response to L2 Spec. I (G2). 


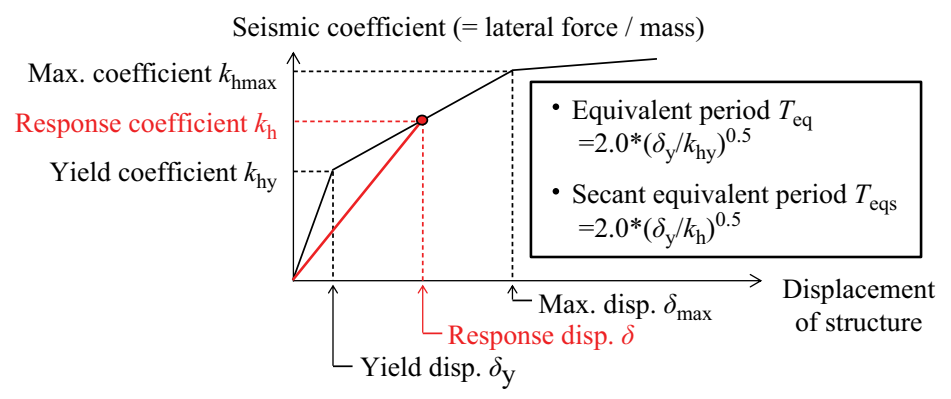

Figure 15: Conceptual schematic of secant equivalent natural period $T_{\text {eqs }}$ using secant rigidity.

of evaluation to develop a method that will be capable of accurately identifying weak structures that can compromise the vehicle running safety during an earthquake in the continuous structure groups.

\section{CONCLUSIONS}

In this study, we investigated the influence of various parameters related to vibration displacement and differential displacement with respect to the vehicle running safety during an earthquake using the analysis program DIASTARS III that can consider the dynamic interaction between railway vehicles and railway structures. Additionally, we conducted seismic vehicle running analysis on a model line with $4.8 \mathrm{~km}$ in length. We identified the critical structures that tend to cause derailment. The observations from this study can be summarised as follows:

1. In case of vibration displacement, when structures became nonlinear because of low seismic yield coefficient, the safety limit acceleration for derailment $P G A_{\mathrm{L}}$ apparently increased.

2. In case of differential displacement, the safety limit rotation angle for derailment became low at high train speeds and when a large number of girders was observed. A comparison of various span lengths, clarified that the lowest safety limit rotation angle was a $20-\mathrm{m}$ span.

3. A simulation of the vehicle running safety in a continuous structure group during an earthquake depicted the derailment locations and the dominant factor for derailment.

4. A new index was proposed to analyse the derailment location and the dominant factor that contribute to causing derailment. It was observed that the identified derailment locations based on the index were good agreement with those of the derail numerical analysis. Also, it was found that identifying the contribution on the vibration displacement and differential displacement to derailment based on the structural response and locating the weak structures in the structural group was possible using the proposed index. 


\section{REFERENCES}

[1] Sogabe, M., Harada, K. \& Watanabe, T., Vehicle running quality during earthquake on railway viaducts. Proceedings of the International Symposium on Speed-up, Safety and Service Technology for Railway and Maglev Systems (STECH'09), CD-ROM No.360713, 2009.

[2] Sogabe, M. Goto, K., Tokunaga, M. \& Asanuma K., Risk assessment method for trainrunning safety during seismicity on railway line. Proceeding of the Ninth World Congress on Railway Research (WCRR), USB H18P, 2011.

[3] Railway Technical Research Institute, Design Standards for Railway Structures and Commentary (Displacement limits), Maruzen: Tokyo, 2008 (in Japanese).

[4] Wakui, H., Matsumoto, N., Matsuura, A. \& Tanabe, M., Dynamic interaction analysis for railway vehicles and structures. Japan Society of Civil Engineers, 513(I-31), pp. 129-138, 1995. (in Japanese)

[5] Matsumoto, N., Sogabe, M., Wakui, H. \& Tanabe, M., Running safety analysis of vehicles on structures subjected to earthquake motion. Quarterly Report of RTRI, 45(3), pp. 116-122, 2004.

[6] Goto, K., Sogabe, M., Tanabe, M. \& Watanabe, T., Study on contact model between wheel and track structure after derailment. Proceedings of the International Symposium on Speed-up, Safety and Sustainable Technology for Railway and Maglev Systems (STECH 2015), USB, 2015.

[7] Goto, K., Sogabe M., Tanabe, M., Watanabe, T. \& Tokunaga, M., Simple method for analyzing contact between wheelset members and track structures using MBD. Quarterly Report of RTRI, 59(1), pp. 57-64, 2018.

[8] Miyamoto, T., Matsumoto N., Sogabe, M., Shimomura, T., Nishiyama, Y. \& Matsuo, M, Railway vehicle dynamic behavior against large-amplitude track vibration a full-scale experiment and numerical simulation. Quarterly Report of RTRI, 45(3), pp. 111-115, 2004.

[9] Railway Technical Research Institute, Design Standards for Railway Structures and Commentary (Seismic Design), Maruzen: Tokyo, 1999 (in Japanese). 